\title{
The Surface Dynamics of the Initial Oxidation Behavior of CuNi Alloys Studied by in-situ TEM
}

\author{
Z. Li*, L. Sun*, S. J. Ziemak* and J. Yang* \\ * Department of Mechanical Engineering and Materials Science, University of Pittsburgh, \\ Pittsburgh, PA, 15261
}

Our extensive research on $\mathrm{Cu}$ and $\mathrm{Cu}-\mathrm{Au}$ oxidation by primarily in situ ultra high vacuum transmission electron microscope (UHV-TEM) have demonstrated that oxidation involves nucleation and growth, surface diffusion and solid state reactions, and bears a striking resemblance to heteroepitaxy where strain plays a critical role in the morphological development of the oxide islands [1-3]. As an extension of this work, we are currently visualizing the oxidation of $\mathrm{Cu}-\mathrm{Ni}$ alloys, where the two components are $100 \%$ solid-soluble down to $\sim 300{ }^{\circ} \mathrm{C}$ but $\mathrm{Cu}_{2} \mathrm{O}$ and $\mathrm{NiO}$ show limited miscibility. Nickel oxide, which has the cubic $\mathrm{NaCl}$ crystal structure, has a more negative standard free energy of formation than $\mathrm{Cu}_{2} \mathrm{O}$, which is simple cubic, and is expected to form more readily. Depending on the environmental $\mathrm{pO}_{2}$ and temperature, either one or both components of the alloy will oxidize, thus enabling a systematic determination of the effects of composition on the oxide phase development during oxidation.

Single crystal $80 \mathrm{~nm}(001) \mathrm{Cu}-24 \% \mathrm{Ni}$ films were produced by co-sputtering $\mathrm{Cu}(99.999 \%)$ and $\mathrm{Ni}$ $(99.999 \%)$ onto irradiated $(001) \mathrm{NaCl}$ with an AJA sputtering system, where the base pressure was $10^{-8}$ Torr. The selected deposition rate was $1 \AA$ per second, as monitored by a quartz crystal microbalance (QCM), and the substrate temperature was held at $270 \sim 300{ }^{\circ} \mathrm{C}$ within an Ar atmosphere of 5 mTorr during deposition. The in situ UHV-TEM is a specially modified JEOL 200 CX with a top entry sample holder. The additional pumping on the column of the microscope consists of a combined Thermionics ion/liquid nitrogen cooled sublimation pump and a Balzers turbo molecular pump. Furthermore, a cryoshield surrounds the specimen cartridge which is cooled via conduction through a $\mathrm{Cu}$ wire to a cold finger held at liquid nitrogen or liquid helium temperature. The pressure in the sample region was determined by an ion gauge attached above the pole piece. The $\mathrm{Cu}-\mathrm{Ni}$ film was removed from the $\mathrm{NaCl}$ substrate by floatation in de-ionized water, washed and then mounted onto a specially prepared $\mathrm{Si}$ mount. The Si mount and the modified specimen holder allow for resistive heating of the specimen up to $1000{ }^{\circ} \mathrm{C}$ in situ. Scientific grade oxygen gas of $99.999 \%$ purity was admitted into the column of the microscope through the leak valve at a partial pressure between $5 \times 10^{-5}$ and 760 Torr.

In remarkable contrast to our previous observations of $\mathrm{Cu}$ and $\mathrm{Cu}-\mathrm{Au}$ oxidation: 1) a second rapid nucleation of compact and dense oxide islands occurred and 2) polycrystalline oxides formed, where only cube-on-cube epitaxial $\mathrm{Cu}_{2} \mathrm{O}$ islands nucleated on $\mathrm{Cu}(001)$ and $\mathrm{CuAu}(001)$ for all temperatures and pressures studied. We speculate that the surface segregation of $\mathrm{Cu}$ and $\mathrm{Ni}$ towards or away, respectively, from the alloy surface during oxidation could disrupt the surface and cause polycrystalline oxide formation. Furthermore, the formation and evolution of oxide islands and their oxidation dynamics will be studied as a function of increasing Ni concentration in the $\mathrm{Cu}-\mathrm{Ni}$ alloys both in situ and ex situ experiments, including XRD.

\section{Reference}

[1] Yang, J. C.; Yeadon, M.; Kolasa, B.; Gibson, J. M., Oxygen surface diffusion in 3-D $\mathrm{Cu}_{2} \mathrm{O}$ growth on $\mathrm{Cu}(001)$ thin films. Applied Physics Letters 1997, 70 (26), 3522-3524.

[2] Zhou, G. W.; Slaughter, W. S.; Yang, J. C., Terraced Holow Oxide Pyramids. Physical Review Letters 2005, 94, 246101-4. 
[3] Zhou, G. W.; Yang, J. C., The initial stages of $\mathrm{Cu}(110)$ oxidation investigated by in situ UHV-TEM. Surface Science 2003, 531, 359-367.
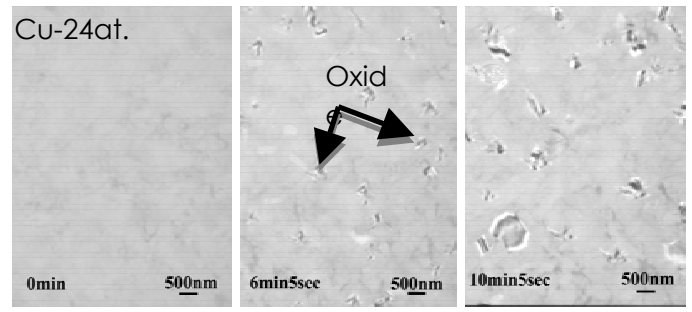

Figure 1. Bright-field images of the in situ oxidation of $\mathrm{Cu}-24$ at $\% \mathrm{Ni}(001)$ at $\mathrm{T}=500^{\circ} \mathrm{C}$ and $\mathrm{P}\left(\mathrm{O}_{2}\right)=5 \times 10^{-}$ ${ }^{4}$ torr. (a) As-clean, (b) 6 and (c) 10 minutes after oxygen was introduced.
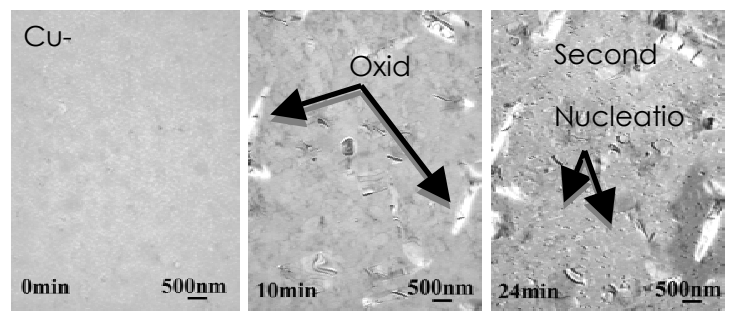

Figure 2. Bright-field images of the in situ oxidation of $\mathrm{Cu}-24 \mathrm{at} \% \mathrm{Ni}(001)$ at $\mathrm{T}=600^{\circ} \mathrm{C}$ and $\mathrm{P}\left(\mathrm{O}_{2}\right)=5 \times 10^{-4}$ torr. (a) As-clean, (b) 10 and (c) 24 minutes after oxygen was introduced.

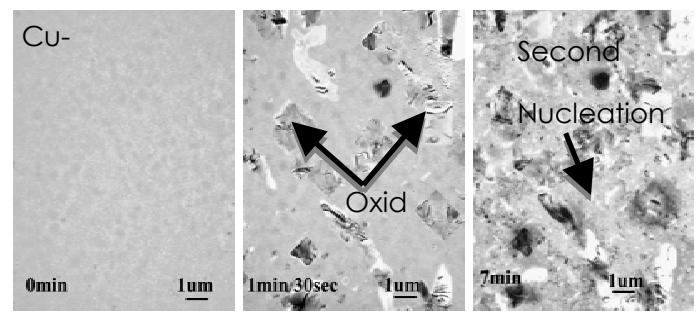

Figure 3. Bright-field images of the in situ oxidation of $\mathrm{Cu}-24 \mathrm{at} \% \mathrm{Ni}(001)$ at $\mathrm{T}=700^{\circ} \mathrm{C}$ and $\mathrm{P}\left(\mathrm{O}_{2}\right)=5 \times 10^{-4}$ torr. (a) As-clean, (b) 1.5 and (c) 7 minutes after oxygen was introduced.


Figure 4. Selected area electron diffraction pattern of $\mathrm{Cu}-24 \mathrm{at} \% \mathrm{Ni}(001)$ film before and after oxidation at $\mathrm{P}\left(\mathrm{O}_{2}\right)=5 \times 10^{-4}$ torr and $\mathrm{T}=600^{\circ} \mathrm{C}$, where the index (111) indicates both $\mathrm{Cu}_{2} \mathrm{O}(111)$ and $\mathrm{NiO}(111)$, similarly for (200) and (220). Similar polycrystalline diffraction patterns were observed for $\mathrm{T}=500^{\circ} \mathrm{C}$ and $700^{\circ} \mathrm{C}$.

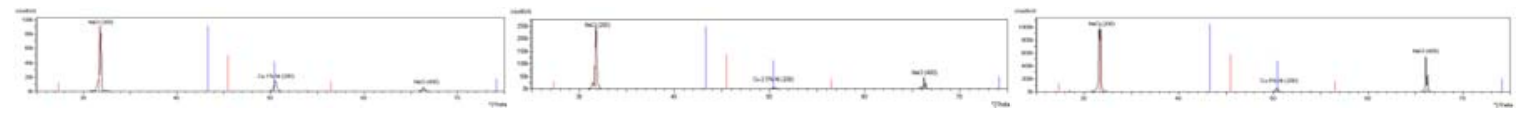

Figure 5. XRD diagram of $\mathrm{Cu}-1$ at $\% \mathrm{Ni}, \mathrm{Cu}-2.5 \mathrm{at} \% \mathrm{Ni}$ and $\mathrm{Cu}-5 \mathrm{at} \% \mathrm{Ni}$ film before in situ and ex situ oxidation. 